Article

\title{
Development of Surface Molecularly Imprinted Polymers as Dispersive Solid Phase Extraction Coupled with HPLC Method for the Removal and Detection of Griseofulvin in Surface Water
}

\author{
Kamran Bashir, Zhimin Luo, Guoning Chen, Hua Shu, Xia Cui, Wen Li, Wang Lu and Qiang Fu * \\ School of Pharmacy, Xi'an Jiaotong University, Xi'an 710061, China; kamranpharmacist27@gmail.com (K.B.); \\ luozm0905@xjtu.edu.cn (Z.L.); chengn1992@stu.xjtu.edu.cn (G.C.); shuhuas@stu.xjtu.edu.cn (H.S.); \\ cuixia0415@stu.xjtu.edu.cn (X.C.); liwen19940820@stu.xjtu.edu.cn (W.L.); wanglu0914@stu.xjtu.edu.cn (W.L.) \\ * Correspondence: fuqiang@mail.xjtu.edu.cn; Tel.: +86-13991998825
}

Received: 14 November 2019; Accepted: 19 December 2019; Published: 24 December 2019

\begin{abstract}
Griseofulvin (GSF) is clinically employed to treat fungal infections in humans and animals. GSF was detected in surface waters as a pharmaceutical pollutant. GSF detection as an anthropogenic pollutant is considered as a possible source of drug resistance and risk factor in ecosystem. To address this concern, a new extraction and enrichment method was developed. GSF-surface molecularly imprinted polymers (GSF-SMIPs) were prepared and applied as solid phase extraction (SPE) sorbent. A dispersive solid phase extraction (DSPE) method was designed and combined with HPLC for the analysis of GSF in surface water samples. The performance of GSF-SMIPs was assessed for its potential to remove GSF from water samples. The factors affecting the removal efficiency such as sample $\mathrm{pH}$ and ionic strength were investigated and optimized. The DSPE conditions such as the amount of GSF-SMIPs, the extraction time, the type and volume of desorption solvents were also optimized. The established method is linear over the range of $0.1-100 \mu \mathrm{g} / \mathrm{mL}$. The limits of detection and quantification were 0.01 and $0.03 \mu \mathrm{g} / \mathrm{mL}$ respectively. Good recoveries $(91.6-98.8 \%)$ were achieved after DSPE. The intra-day and inter-day relative standard deviations were 0.8 and $4.3 \%$ respectively. The SMIPs demonstrated good removal efficiency $(91.6 \%)$ as compared to powder activated carbon (67.7\%). Moreover, the SMIPs can be reused 10 times for water samples. This is an additional advantage over single-use activated carbon and other commercial sorbents. This study provides a specific and sensitive method for the selective extraction and detection of GSF in surface water samples.
\end{abstract}

Keywords: dispersive solid phase extraction; griseofulvin; HPLC; removal and analysis; pharmaceutical pollutants; surface water

\section{Introduction}

The presence of pharmaceutical substances in the environmental waters has become a global hazard $[1,2]$. The major sources of these contaminations are industries, agriculture and long term drought. The surface water and ground water have been seriously affected by these pollutants. These chemicals enter into the body systems of humans, animals and aquatic strains through the food chain. Their intended or un-intended use and excretion in discharge waters pose potential harmful effects on the public health and aquatic ecosystem [3,4].

Antibiotics, an important group of pharmaceuticals, have been excessively used around the globe. Meanwhile, antibiotic pollution has also posed a major global threat to humans [5]. The easy migration of antibiotics in drinking water causes serious drug resistance which brings the environmental risk 
in terms of residual antibiotics released into the ecosystem [6]. Griseofulvin (GSF), one of the major constituents of antibiotics, is among the first discovered oral antifungal drugs and extensively used in treating mycotic infection both in animals and humans. GSF appears as white to pale crystalline powder, odorless and tasteless. It is very less soluble in water and soluble in organic solvents. This drug has been used for more than forty years and is a drug of choice for the treatment of Tinea capitis [7]. GSF new properties like antiviral and anticancer was studied in the mammalian system and revived its clinical use other than an anti-mycotic drug [8-10]. Despite its clinical applications, multiple severe side effects have also been associated with its clinical use [11]. A variety of acute and chronic toxic effects such as teratogenicity, liver and thyroid cancers, embryo toxicity and abnormal germ cell maturation were also reported [12]. Phytotoxic effect on plants, inhibition, delay and abnormalities induced by GSF in stent or have been reported. Hashimoto in 1969 reported GSF as less toxic to fish and aquatic organisms [13-15]. According to literature survey, GSF has been detected in Miño River, Spain from a rural site at a maximum concentration of $37.6 \mathrm{ng} / \mathrm{L} \mathrm{[16].} \mathrm{Another} \mathrm{study} \mathrm{reported} \mathrm{its} \mathrm{presence} \mathrm{in}$ Romanian surface water samples [17]. GSF was also reported as a surface water and waste waters pharmaceutical pollutant [18-20]. GSF is produced as a byproduct of Penicillium griseofulvum and could be a possible source of continuous excretion in aquatic environment [21]. Additionally, the continuous environmental exposure from water sources may cause unnecessary adverse effects in aquatic environment and can harm animals and humans by food chain. Therefore, its separation and detection in environmental water is crucial. The extraction and estimation of GSF have been reported in food, molds, aquatic strains, [22] but the detection of GSF in Chinese surface water samples was not studied previously.

Considering the threats of GSF in surface water, the general waste water treatment procedures have been handled, such as physical adsorption, oxidation or bioremediation. However, GSF, as a micro-pollutant (whose concentration is extremely low), is hard to be completely removed. Therefore, its detection and removal is still a challenge. Typically, GSF is analyzed or detected by high performance liquid chromatography, gas chromatography and liquid chromatography-mass spectrometry, etc. [23]. Whereas, a reliable sample pretreatment is required before using these instruments. Generally, solid phase extraction (SPE) is used in sample pretreatment. However, the traditional SPE sorbents, such as C18, C8, Florisil, Silica and Charcoal have no selectivity for the targeted compounds [24]. In recent years, molecularly imprinted polymers (MIPs) have been considered as attractive adsorbent to produce artificial receptors which are complementary in size, shape, and functional groups to the template molecules [25]. The MIP prepared by surface imprinting approach has more recognition sites at the surface of material which encourage a quick mass exchange, fast recognition and more recoveries. The surface molecularly imprinted polymers (SMIPs) show great strength at different $\mathrm{pH}$ values, extraordinary mechanical quality at different temperatures, and robustness in various solvents [26]. SPE advanced subdivisions such as dispersive SPE (DSPE), stir-bar sportive extraction, solid phase micro extraction, and single drop micro extraction, are considered as highly selective, less expensive and more environment friendly as compared to conventional extraction methods [27-29]. The dispersive extraction method is designed to increase the surface area between sample solution and sorbents, decrease extraction time and decrease the amount of sorbent by means of dispersion [30-32]. The procedure requires the utilization of exceptionally proficient extraction media so as to keep up or increase the pre-concentration of analytes in samples and by using just few milligrams or microliters of extraction media.

The aim of this study was to prepare and apply SMIPs as DSPE sorbents for specific and selective separation and enrichment of GSF from complex matrix, and to establish the SMIP-DSPE coupled to HPLC method for the sensitive and selective analysis of GSF in surface water samples. We also studied the factors affecting removal efficiency and optimized the DSPE conditions. This is the first report for the selective removal and extraction of GSF from surface water samples. 


\section{Methods}

\subsection{Chemical and Instruments}

GSF, voriconazole and miconazole were purchased from Aladdin Co. (Beijing, China). Ultra-pure water was purified with Molement 1805 b (Shanghai, China). Methanol and acetonitrile were of HPLC grade. All other chemicals used in this study were supplied from local suppliers and of analytical grade.

The HPLC analysis was performed with a Shimadzu LC-2010AHT series HPLC (Kyoto, Japan) and a Lab-Solution workstation. The shaking was performed by a SHA-C Vapour-Bathing Constant Temperature Vibrator (Changzhou, China). For chromatographic separation, a Promasil $\mathrm{C}_{18}$ column $(250 \mathrm{~mm} \times 4.6 \mathrm{~mm}, 5 \mu \mathrm{m})$ was used. The mobile phase was methanol-water $(70: 30, v / v \%)$ and a flow rate of $1.0 \mathrm{~mL} / \mathrm{min}$ was used. The detection wavelength was $291 \mathrm{~nm}$, and the column oven temperature was set at $30^{\circ} \mathrm{C}$.

\subsection{Drug Standards, Spiked Samples and Surface Water Collection}

A stock solution $(1000 \mu \mathrm{g} / \mathrm{mL})$ of GSF was prepared in methanol. Further the working standard solutions of $0.1,1,10,25,50,75,100,200,300,400,500 \mu \mathrm{g} / \mathrm{mL}$ prepared by serially diluted with methanol-water $(70: 30, v / v)$.

The surface water collected from Qing Ling Lake in Xi'an, Shaanxi province was filtered through a membrane of $0.45 \mu \mathrm{m}$ pore size. The surface water samples and deionized water samples were spiked with GSF working standard solution concentrations $(0.1-500 \mu \mathrm{g} / \mathrm{mL})$ for further analysis.

\subsection{Preparation and Characterization}

The GSF-SMIPs were prepared by using modified silica gel particles as a support material and by using non-covalent surface imprinting method. GSF $(0.5 \mathrm{mM})$ was added in toluene $(20 \mathrm{~mL})$, methacrylic acid ( $2 \mathrm{mM})$ was used as functional monomer, ethylene glycol dimethacrylate $(10 \mathrm{mM})$ as cross linker, 2,2' -azobisisobutyronitrile $(16.4 \mathrm{mg})$ as an initiator and toluene was used as a solvent. After polymerization the polymers were collected, washed and template was removed by using methanol-acetic acid (4:1). The surface non imprinted polymers (SNIPs) were prepared without template drug by the same method. Detail preparation and characterization were performed and discussed in our previous work [33].

\subsection{Removal of GSF in Surface Water}

\subsubsection{Removal Efficiency in Surface Water and Deionized Water Samples}

In this experiment, $10 \mathrm{mg}$ of SMIPs were added in $10 \mathrm{~mL}$ flask containing $10.0 \mathrm{~mL}$ of spiked surface water and deionized water of different concentrations (10-500 $\mu \mathrm{g} / \mathrm{mL})$. After being shaken for $30 \mathrm{~min}$ at room temperature, the samples were centrifuged and filtered and were analyzed by HPLC. The adsorption quantities $\mathrm{Q}(\mu \mathrm{g} / \mathrm{mg})$ of SMIPs and SNIPs were estimated by the following equation.

$$
\mathrm{Q}=\left(\mathrm{C}_{\mathrm{o}}-\mathrm{C}_{\mathrm{f}}\right)^{*} \mathrm{~V} / \mathrm{m}
$$

' $\mathrm{C}_{\mathrm{o}}$ ' is the initial concentration and ' $\mathrm{C}_{\mathrm{f}}$ ' $(\mu \mathrm{g} / \mathrm{mL})$ is the concentration after adsorption, ' $\mathrm{V}$ ' is volume of drug solution and ' $\mathrm{m}$ ' ( $\mathrm{mg}$ ) is the amount of polymer used. The adsorbed amount was the measure of removal efficiency. All the experiments were performed in triplicate.

\subsubsection{Effect of $\mathrm{pH}$}

To examine the effect of $\mathrm{pH}$ on removal efficiency, we adjusted the $\mathrm{pH}$ of drug solution $(100 \mu \mathrm{g} / \mathrm{mL})$ from 1-10 by adding $\mathrm{HCl}$ or $\mathrm{NaOH}$. Then $10.0 \mathrm{~mL}$ drug solutions of different $\mathrm{pH}$ were added in separate flasks. In each flask $50 \mathrm{mg}$ of SMIPs and $50 \mathrm{mg}$ SNIPs were dispersed. Each flask was shaken 
for $30 \mathrm{~min}$ at room temperature. The samples were centrifuged and filtered and analyzed by HPLC. The final removal $(\%)$ was determined.

\subsubsection{Effect of Ionic Strength}

In this experiment, $\mathrm{NaCl}$ salt $(0,1,2,3,4,5$ and $6 \%)$ was added in drug solution $(100 \mu \mathrm{g} / \mathrm{mL})$. After this, $50 \mathrm{mg}$ of SMIPs and SNIPs were added in the different reaction flasks. The flasks were shaken for $30 \mathrm{~min}$ at room temperature. After this the samples were centrifuged and filtered. The removal (\%) was calculated.

\subsubsection{Removal Efficiency of SMIPs, SNIPs and Activated Carbon}

For this experiment, powder activated carbon PAC was treated with $0.1 \mathrm{~mol} / \mathrm{L}$ of hydrochloric acid in order to remove ions [34] After this, the $\mathrm{pH}$ of the PAC was neutralized by washing with deionized water. The PAC was dried at $100^{\circ} \mathrm{C}$. After this, $50 \mathrm{mg}$ of SMIPs, SNIPs and PAC were added in different reaction flasks and then $10 \mathrm{~mL}$ of drug solution $(100 \mu \mathrm{g} / \mathrm{mL})$ were added in respective flasks. The flasks were shaken for $1 \mathrm{~h}$, at room temperature; then the samples were separated, centrifuged and filtered. The removal (\%) was measured.

\subsection{DSPE Procedure for the Extraction of GSF}

In this experiment we utilized GSF-SMIPs as a selective sorbent and a DSPE method was combined with HPLC for the analysis of GSF in water samples.

The DSPE procedure for extraction of GSF was as followed: $50 \mathrm{mg}$ of SMIPs was dispersed in $5 \mathrm{~mL}$ spiked surface water sample in a $10 \mathrm{~mL}$ reaction flask. The reaction flask was shaken for $30 \mathrm{~min}$ at 150 revolutions per minute. After $30 \mathrm{~min}$ the supernatant was removed. After this washing solvent was added and allowed to disperse for $30 \mathrm{~min}$. After $30 \mathrm{~min}$, the solvent was removed and sorbent material remained in the flask. Further for extraction, $1 \mathrm{~mL}$ of desorption solvent was added in reaction flask and was shaken for $15 \mathrm{~min}$. After $15 \mathrm{~min}$, the supernatant was centrifuged, filtered, transferred into $1 \mathrm{~mL}$ vial, dried completely under nitrogen stream, reconstituted with $1 \mathrm{~mL}$ methanol and $10 \mu \mathrm{L}$ of this solution was injected into HPLC for analysis. Figure 1 shows the procedure for selective extraction of GSF from surface water samples.
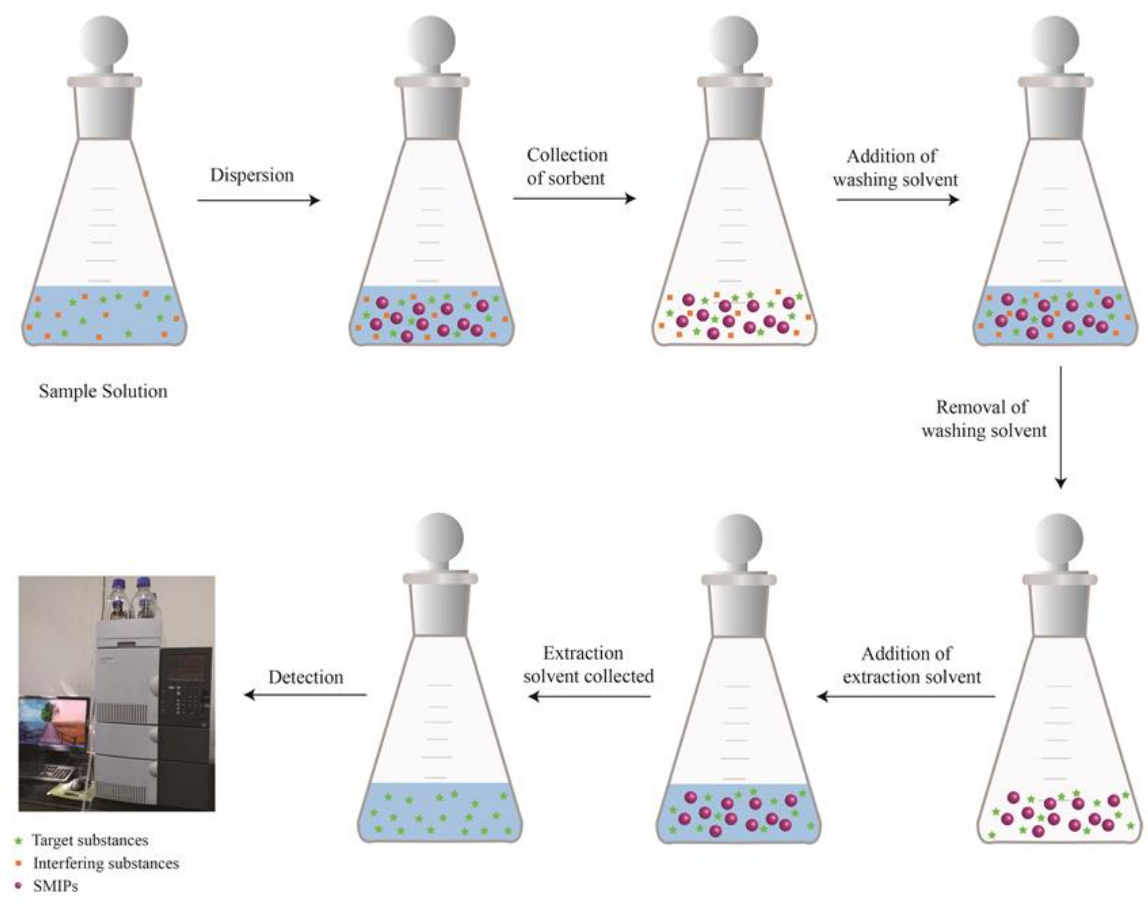

Figure 1. Graphical abstract of dispersive solid phase extraction (DSPE) method. 


\section{Results and Discussion}

\subsection{Removal of GSF from Surface Water}

The practicality of applying SMIPs for the removal of GSF from surface water was measured by matching the adsorption isotherm in surface water and deionized water samples. The adsorption amount is a measure of removal efficiency. The adsorption amount of SMIPs in surface water sample was $76.4 \mu \mathrm{g} / \mathrm{mg}$, while it was $119.1 \mu \mathrm{g} / \mathrm{mg}$ in deionized water (Figure 2A). The decline in the SMIPs adsorption efficiency for GSF in surface water may be ascribed to the differences in $\mathrm{pH}$ or higher amount of ions. Therefore, it was desired to determine the effect of $\mathrm{pH}$ and ionic content on the removal efficiency of SMIPs.

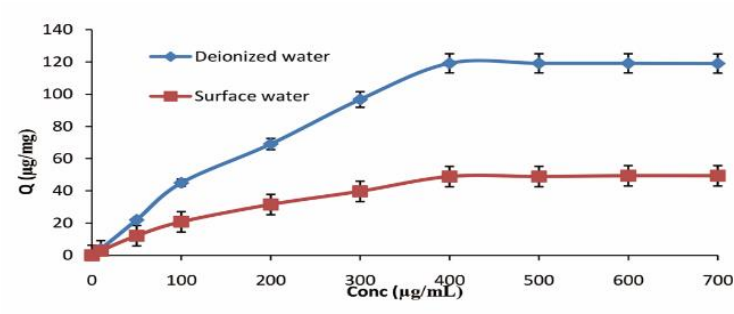

A

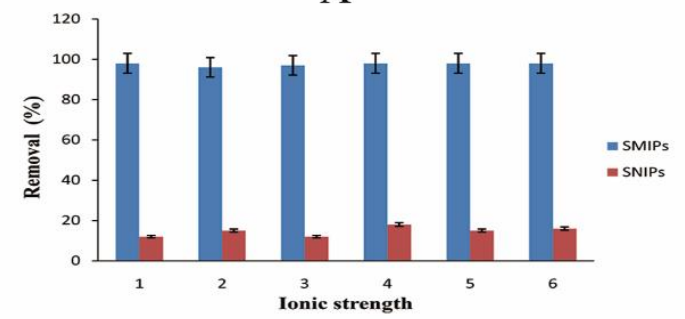

C

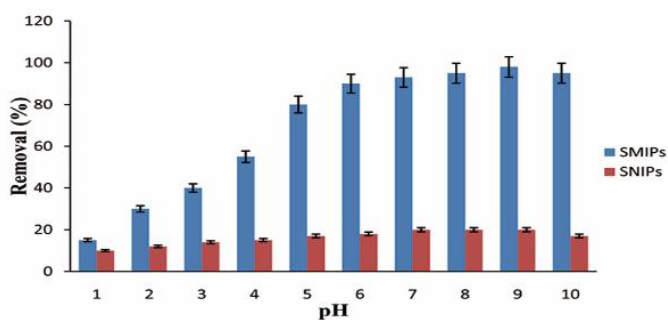

B

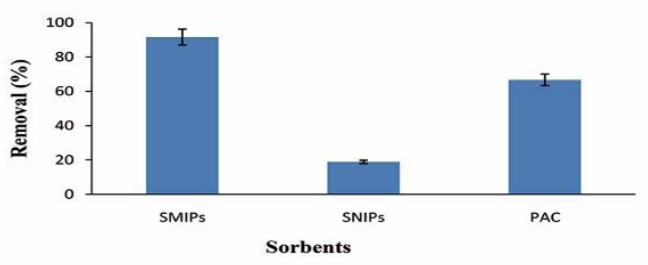

D

Figure 2. Removal of GSF. (A) Removal efficiency in surface and deionized water; (B) effect of $\mathrm{pH}$ on removal efficiency; (C) effect of ionization on removal efficiency; (D) comparison of different sorbent materials.

\subsubsection{Effect of $\mathrm{pH}$}

The removal efficiency of the drug largely depends upon $\mathrm{pH}$ value of water samples. Therefore, we determined the removal rate of GSF at different $\mathrm{pH}$ values. The results showed that removal rate of GSF range were maximum at $\mathrm{pH}$ value of 9 (Figure $2 \mathrm{~B}$ ). This may be due to the reason that the hydrophobic interaction and binding affinity of drug and specific sites at this $\mathrm{pH}$ range was maximum. Additionally, with an increase in $\mathrm{pH}$, an increase in the adsorption of basic compounds to the methacrylic acid-type of polymers was resulted [35]. The removal efficiency of GSF decreased significantly with the decrease of $\mathrm{pH}$ when the $\mathrm{pH}$ was between $1-4$. This phenomenon could be explained by the ionization of GSF. The GSF pKa value was >9 [16]. Ionization occurred for GSF under strong acidic condition. This resulted in the decrease of removal amount.

\subsubsection{Effect of Ionic Strength}

We determined the effect of ionic strength on the removal efficiency of SMIPs. The results revealed that an increase or decrease of ionic strength did not significantly affect the removal rate of GSF (Figure 2C). In this ionic strength range (0-6\%), the impact of the salting-out effect to GSF was too weak to exert any change in the removal of GSF on the SMIPs. Thus, the ionic strength of surface water samples was not supposed to exert any significant effect on the removal of GSF by SMIPs and SNIPs. 


\subsubsection{Comparison of Removal Efficiency of SMIPs, SNIPs and Activated Carbon}

The removal rate of GSF-SMIPs was compared with that of SNIPs, and PAC for the treatment of GSF. Figure 2D shows that the SMIPs had higher removal rate than SNIPs and PAC. The removal efficiency of SMIPs for GSF was higher (91.6\%) than by PAC (67.7\%). The removal efficiency of GSF did not increase by increasing the amount of PAC. The results demonstrated that SMIPs had a better removal efficiency and selectivity for GSF compared to PAC. Activated carbon removal has been used to remove pharmaceutical pollutants from water [36]. Moreover, the PAC was difficult to regenerate, and tended to saturate at lower loadings [37]. These favorable results made the SMIPs as a better choice for removal of GSF from contaminated waters.

\subsection{Optimization of the DSPE Procedure}

\subsubsection{Amount of SMIPs}

The amount of sorbent matrix had a major effect on the recoveries of target drugs from complex matrix. Therefore, the amounts of SMIPs were investigated in the range of $10-100 \mathrm{mg} / 5 \mathrm{~mL}$. The results (Figure $3 \mathrm{~A}$ ) explained that maximum recovery achieved by using $50 \mathrm{mg} / 5 \mathrm{~mL}$ of SMIPs as sorbents. The recoveries of GSF were not increased by increasing the amount of SMIPs after $50 \mathrm{mg} / 5 \mathrm{~mL}$. Therefore, $50 \mathrm{mg} / 5 \mathrm{~mL}$ were chosen as the final sorbent amount.
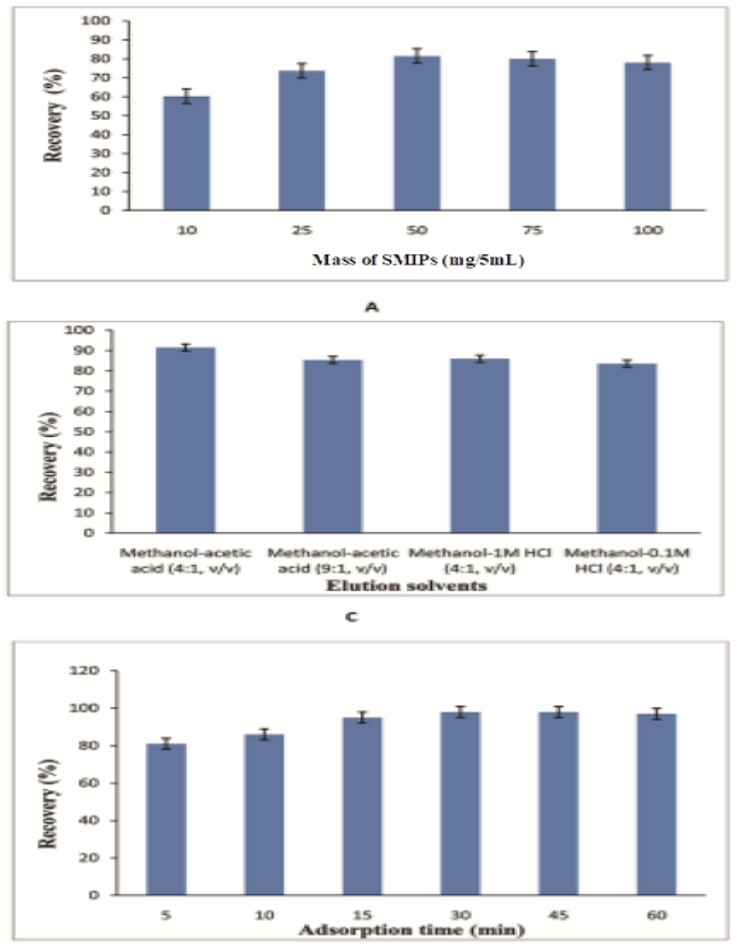

E

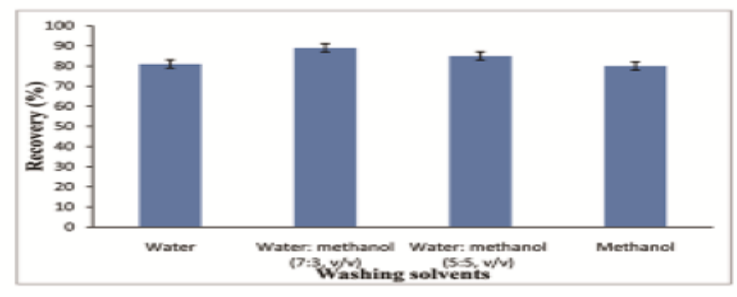

s

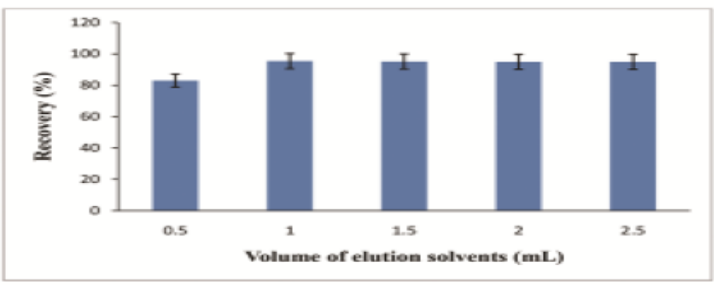

D

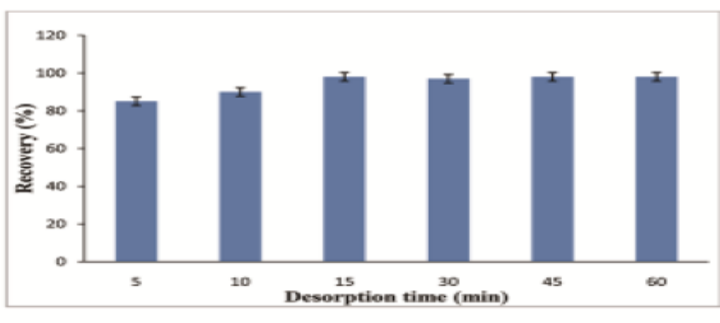

F

Figure 3. Optimization of DSPE procedure (A) Amount of sorbent; (B) washing solvents; (C) elution solvents; (D) volume of elution solvents; (E) time for adsorption; (F) time for desorption.

\subsubsection{Type and Volume of Washing Solvent}

Different washing solvents were used to remove the interference substances and to obtain good recoveries. In this experiment, the washing solvents, including water, water: methanol $(7: 3, v / v)$, water: methanol $(5: 5, v / v)$ and methanol, were optimized. The volume of each washing solvent used in each washing step was $2 \mathrm{~mL}$ and maximum recoveries were as achieved (Figure 3B) by using water: methanol $(7: 3, v / v)$. 


\subsubsection{Type and Volume of Elution Solvent}

The effect of elution solvents on desorption of GSF from SMIPs was investigated. We used methanol as an elution solvent because the GSF is good soluble in methanol. An amount of acid was also optimized in desorption solvent. Subsequently, different types of elution solvents were applied such as methanol-acetic acid $(4: 1, v / v)$, methanol-acetic acid $(9: 1, v / v)$, methanol-1M $\mathrm{HCl}(4: 1, v / v)$, methanol-0.1M HCl $(4: 1, v / v)$. The maximum recovery was achieved by using methanol-acetic acid $(4: 1, v / v)$ (Figure 3C). In the next step, we optimized the volume of elution solvent. Figure 3D shows a $1 \mathrm{~mL}$ volume gave maximum recovery of $95.4 \%$.

\subsubsection{Adsorption and Desorption Time}

The adsorption and desorption time have also been optimized for the efficient extraction of the GSF from samples. So it was studied by changing the vortex time from 5 to $60 \mathrm{~min}$. The recoveries (Figure 3E) increased with the increase of adsorption time until it reached the equilibrium time. Finally, $30 \mathrm{~min}$ was chosen as the adsorption time. In this study, desorption time was also considered by increasing the vortex time from 5 to $60 \mathrm{~min}$. The result (Figure 3F) shows that within $15 \mathrm{~min}$ the maximum recovery was achieved.

\subsection{Selectivity Characteristics of SMIPs}

We evaluated the selectivity of GSF SMIPs with voriconazole and miconazole in aqueous samples. As our main interest was the water remediation, so we determined the selectivity in aqueous phase. The imprint factor for GSF was 2.2 and for voriconazole was 1.2 and for miconazole was 1.4 (Figure 4). The SMIPs demonstrated lower recognition capability for therapeutic analogues. These results suggested the presence of specific sites on the surface of silica particles for GSF. These selective binding sites enhanced the adsorption of analyte from complex samples and decreased the binding of interfering substances [38].
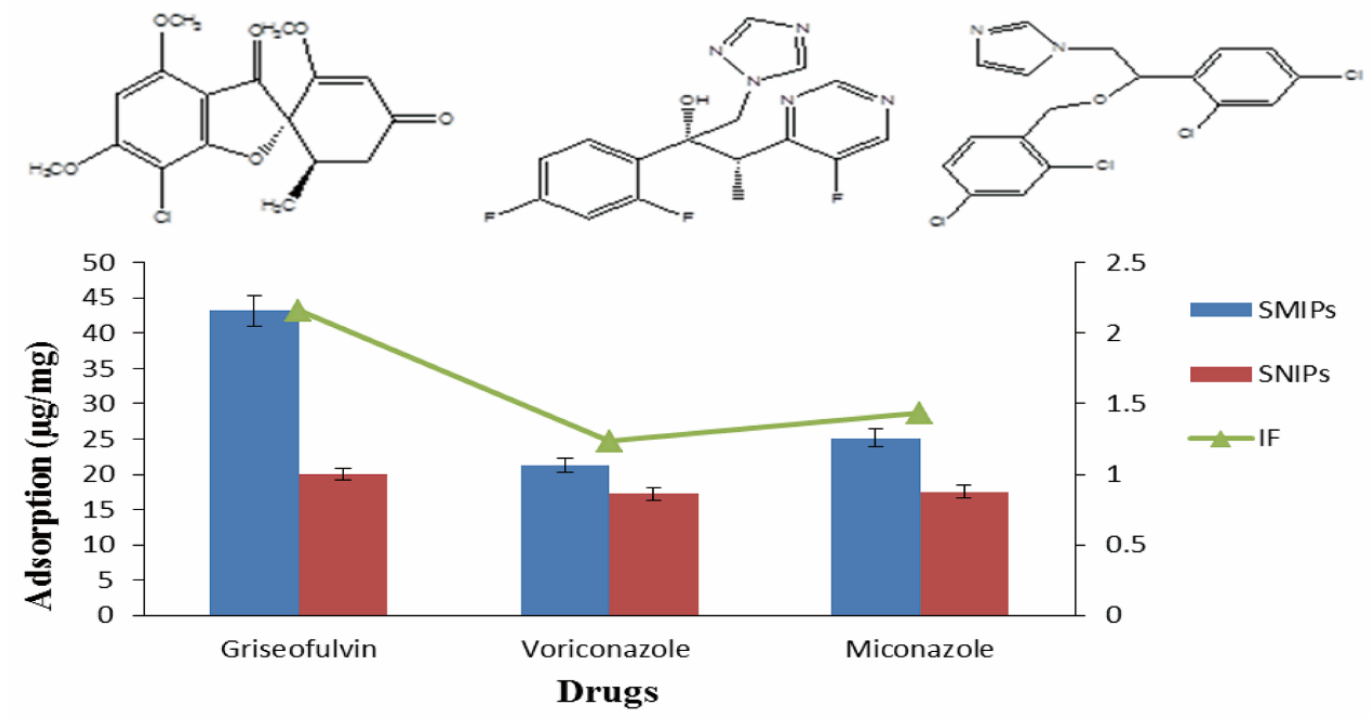

Figure 4. Selectivity of surface molecularly imprinted polymers (SMIPs) and surface non imprinted polymers (SNIPs).

\subsection{Method Validation}

The specificity of HPLC coupled to DSPE was evaluated with GSF standard solution, deionized and spiked surface water samples. The linear calibration curves of GSF in spiked surface water samples were obtained from the concentration range of $0.1-100 \mu \mathrm{g} / \mathrm{mL}$ with a linear calibration curve value $\left(R^{2}=0.9973\right)$. The limit of detection and limit of quantification were $0.01 \mu \mathrm{g} / \mathrm{mL}$ (signal to noise ratio 
$(\mathrm{S} / \mathrm{N}), \mathrm{S} / \mathrm{N}=3)$ and $0.03 \mu \mathrm{g} / \mathrm{mL}(\mathrm{S} / \mathrm{N}=10)$. A good separation of GSF indicated that this method had a good specificity to detect GSF in surface water samples. Method accuracy and precision were established at three concentration levels of samples $(0.1,10,50 \mu \mathrm{g} / \mathrm{mL})$. The intra-day precision was evaluated by three repeated experiments of each spiked sample. Similarly, the inter-day precision was examined by recording the recoveries from spiked samples on three consecutive days. The relative standard deviation RSD- of intraday and inter-day precisions were less than 4.3\% (Table 1).

Table 1. Recovery and precision of griseofulvin (GSF) in deionized and surface water samples.

\begin{tabular}{|c|c|c|c|c|}
\hline \multirow{2}{*}{ Sample } & \multirow{2}{*}{$\begin{array}{l}\text { Spiked Drug } \\
\text { Conc. }(\mu \mathrm{g} / \mathrm{mL})\end{array}$} & \multirow{2}{*}{$\begin{array}{l}\text { Recoveries } \\
\text { (\%) } n=3\end{array}$} & \multicolumn{2}{|c|}{ Precision (RSD \%, $n=3$ ) } \\
\hline & & & Intra-Day & Inter-Day \\
\hline \multirow{4}{*}{ Deionized Water } & 0.0 & ND & 0.0 & 0.0 \\
\hline & 0.1 & 96.9 & 0.3 & 0.7 \\
\hline & 10 & 98.8 & 0.2 & 0.8 \\
\hline & 50 & 93.9 & 0.06 & 0.4 \\
\hline \multirow{4}{*}{ Surface Water } & 0.0 & ND & 0.0 & 0.0 \\
\hline & 0.1 & 95.5 & 0.8 & 2.1 \\
\hline & 10 & 98.6 & 1.5 & 3.5 \\
\hline & 50 & 91.6 & 1.8 & 4.3 \\
\hline
\end{tabular}

$\mathrm{ND}=$ not detected .

\subsection{Sample Application}

The water samples, spiked surface water samples and spiked deionized water samples were subjected to extraction by using DSPE method. The DSPE had good recoveries (91.6-98.8\%) at the three concentration levels (Table 1). Figure 5 explains the chromatograms of standard drug sample, spiked surface water sample by using SNIPs after DSPE, spiked surface water samples by using SMIPs after DSPE and deionized water samples by using SMIPs after DSPE. The results of chromatogram (Figure 5) showed that after DSPE application there was a decrease of the amount of interference substances, and high enrichment of targets and good recoveries achieved by using SMIPs as sorbent material. So, a simple, selective, cost effective DSPE method can be used to extract, enrich, remove interface substances and detect the GSF from complex surface water samples.

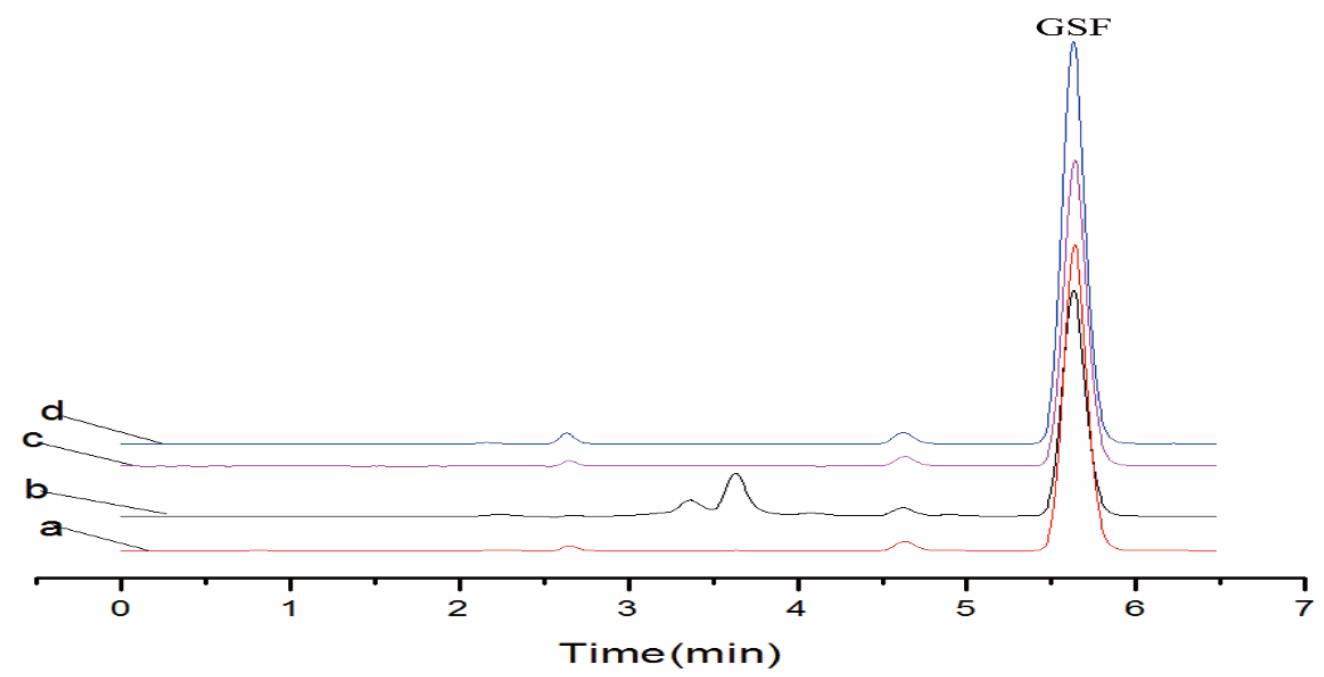

Figure 5. Recovery chromatograms of drug standard, surface and deionized water samples. (a) Drug standard $10 \mu \mathrm{g} / \mathrm{mL}$; (b) spiked surface water sample by using SNIPs after DSPE; (c) spiked surface water sample by using SMIPs after DSPE; (d) spiked deionized water sample by using SMIPs after DSPE. 


\subsection{Reusability of Sorbent}

The SMIPs were employed to estimate the reusability and stability of SMIP-DSPE in aqueous samples. The result showed (Figure S1 that the SMIPs can be used ten times for binding/removing GSF in water samples. After ten cycles, the recoveries of GSF were all $\geq 73.1 \%$. It indicated that SMIPs had a good reusability for water treatment and can be used several times without any significant performance loss.

\subsection{Comparison with Previous Methods}

The SMIP-DSPE method matched in extraction effectiveness and sensitivity with already reported methods [33,39-41]. The results (Table 2) validated that the developed SMIP-DSPE method has better recoveries as compared with previously reported methods. The method was fully validated according to the guidelines and presented a linear, specific, selective, reproducible and efficient method for detection and monitoring of GSF in water samples. In the DSPE method, less amount of sorbent and desorption solvent was used. Moreover extraction efficiency improved, extraction time reduced and a fast and reliable analytical method was established. The reusability of SMIPs in water samples was 10 times. Therefore, this DSPE extraction process is fast, selective, accurate, specific, simple, and reproducible.

Table 2. Comparison with previous methods.

\begin{tabular}{|c|c|c|c|c|c|c|}
\hline Method & Sample & $\begin{array}{c}\text { Sample } \\
\text { Volume Used }\end{array}$ & Precision & $\begin{array}{c}\text { Limit of Detection } \\
(\mathrm{ng} / \mathrm{mL})\end{array}$ & $\begin{array}{c}\text { Recoveries } \\
(\%)\end{array}$ & References \\
\hline $\begin{array}{c}\text { Gas Liquid } \\
\text { Chromatography, } \\
\text { Liquid-Liquid } \\
\text { extraction GLC, LLE }\end{array}$ & $\begin{array}{l}\text { Human } \\
\text { Plasma }\end{array}$ & 1 & NA & 6 & $97-107$ & 39 \\
\hline LC-MS/MS, SPE & $\begin{array}{l}\text { Human } \\
\text { Plasma }\end{array}$ & 0.5 & $7.5 \%$ & 20 (LLOQ) & 87.36 & 40 \\
\hline $\begin{array}{l}\text { HPLC-Fluorescence, } \\
\text { LLE }\end{array}$ & Rat Plasma & 0.1 & $3.0-7.5 \%$ & 1 & 99.20 & 41 \\
\hline HPLC-UV, SMISPE & Rat Plasma & 0.5 & $0.9-4.5 \%$ & 20 & 97.7 & 33 \\
\hline $\begin{array}{c}\text { HPLC-UV, } \\
\text { SMIP-DSPE }\end{array}$ & $\begin{array}{l}\text { Surface } \\
\text { Water } \\
\text { Sample }\end{array}$ & 5 & $0.2-4.3 \%$ & 10 & 98.8 & $\begin{array}{l}\text { Current } \\
\text { work }\end{array}$ \\
\hline
\end{tabular}

NA = not available; LLOQ = lowest limit of quantification.

\section{Conclusions}

In this work, GSF-SMIPs were successfully applied for the pre-concentration, extraction and removal of GSF from environmental water samples. SMIPs had better removal efficiency as compared to the activated carbon and can be used several times which demonstrated its clear advantage over other adsorbent materials. Under optimized conditions, a fast and sensitive method for the determination of GSF was established by coupling with HPLC. This method also offers better kinetic profile, performances and recoveries compared with previous established methods. The method has been applied for analysis of GSF in real water samples. The results suggest that SMIPs are superior and selective adsorbent material for the separation and detection of GSF in environmental water samples. This work provides a new method for the separation, monitoring and detection and removal of pharmaceutical pollutants from water samples.

Supplementary Materials: The following are available online at http://www.mdpi.com/1660-4601/17/1/134/s1, Figure S1: Reusability of SMIPs.

Author Contributions: Data curation, K.B., W.L. (Wen Li) and W.L. (Wang Lu); Formal analysis, Z.L., G.C. and X.C.; Funding acquisition, Q.F.; Investigation, K.B.; Methodology, K.B. and G.C.; Project administration, Z.L. and Q.F.; Resources, K.B., H.S., X.C. and Q.F.; Software, K.B. and W.L. (Wen Li); Supervision, Q.F.; Validation, K.B. and H.S.; Visualization, K.B. and G.C.; Writing-original draft, Q.F.; Writing-review \& editing, K.B. and Z.L. All authors have read and agreed to the published version of the manuscript. 
Funding: The authors wish to thank the China scholarship council for generous scholarship and the National Natural Science Foundations of China (Grant Nos. 81773689, 81573391, 81603073) for funding this project.

Conflicts of Interest: The authors declared no conflict of interest.

$\begin{array}{ll}\text { Abbreviations } \\ \text { DSPE } & \text { Dispersive solid phase extraction } \\ \text { GSF } & \text { Griseofulvin } \\ \text { IF } & \text { Imprinting factor } \\ \text { MIPs } & \text { Molecularly imprinted polymers } \\ \text { PAC } & \text { Powder activated carbon } \\ \text { SMIPs } & \text { Surface molecularly imprinted polymers } \\ \text { SNIPs } & \text { Surface non-molecularly imprinted polymers } \\ \text { SPE } & \text { Solid phase extraction }\end{array}$

\section{References}

1. Reis, E.O.; Foureaux, A.F.S.; Rodrigues, J.S.; Moreira, V.R.; Lebron, Y.A.R.; Santos, L.V.S.; Amaral, M.C.S.; Lange, L.C. Occurrence, removal and seasonal variation of pharmaceuticals in Brasilian drinking water treatment plants. Environ. Pollut. 2019, 250, 773-781. [CrossRef] [PubMed]

2. González-Alonso, S.; Merino, L.M.; Esteban, S.; López de Alda, M.; Barceló, D.; Durán, J.J.; López-Martínez, J.; Aceña, J.; Pérez, S.; Mastroianni, N.; et al. Occurrence of pharmaceutical, recreational and psychotropic drug residues in surface water on the northern antarctic peninsula region. Environ. Pollut. 2017, 229, 241-254. [CrossRef] [PubMed]

3. Lima, E.C.; Sophia, C.A. Removal of emerging contaminants from the environment by adsorption. Ecotoxicol. Environ. Saf. 2018, 150,1-17.

4. Balakrishna, K.; Rath, A.; Praveenkumarreddy, Y.; Guruge, K.S.; Subedi, B. A review of the occurrence of pharmaceuticals and personal care products in Indian water bodies. Ecotoxicol. Environ. Saf. 2017, 137, 113-120. [CrossRef]

5. Kumar, M.; Jaiswal, S.; Sodhi, K.K.; Shree, P.; Singh, D.K.; Agrawal, P.K.; Shukla, P. Antibiotics bioremediation: Perspectives on its ecotoxicity and resistance. Environ. Int. 2019, 124, 448-461. [CrossRef]

6. Szymańska, U.; Wiergowski, M.; Sołtyszewski, I.; Kuzemko, J.; Wiergowska, G.; Woźniak, M.K. Presence of antibiotics in the aquatic environment in Europe and their analytical monitoring: Recent trends and perspectives. Microchem. J. 2019, 147, 729-740. [CrossRef]

7. Petersen, A.B.; Rønnest, M.H.; Larsen, T.O.; Clausen, M.H. The chemistry of Griseofulvin. Chem. Rev. 2014, 114, 12088-12107. [CrossRef]

8. Rønnest, M.H.; Raab, M.S.; Anderhub, S.; Boesen, S.; Kramer, A.; Larsen, T.O.; Clausen, M.H. Disparate SAR data of griseofulvin analogues for the dermatophytes Trichophyton mentagrophytes, T. rubrum, and MDA-MB-231 cancer cells. J. Med. Chem. 2012, 55, 652-660. [CrossRef]

9. Dumontet, C.; Jordan, M.A. Microtubule-binding agents: A dynamic field of cancer therapeutics. Nat. Rev. Drug Discov. 2010, 9, 790. [CrossRef]

10. Rathinasamy, K.; Jindal, B.; Asthana, J.; Singh, P.; Balaji, P.V.; Panda, D. Griseofulvin stabilizes microtubule dynamics, activates p53 and inhibits the proliferation of MCF-7 cells synergistically with vinblastine. BMC Cancer 2010, 10, 213. [CrossRef]

11. Knasmüller, S.; Parzefall, W.; Helma, C.; Kassie, F.; Ecker, S.; Schulte-Hermann, R. Toxic effects of griseofulvin: Disease models, mechanisms, and risk assessment. Crit. Rev. Toxicol. 1997, 27, 495-537. [CrossRef] [PubMed]

12. Liu, K.; Yan, J.; Sachar, M.; Zhang, X.; Guan, M.; Xie, W.; Ma, X. A metabolomic perspective of griseofulvin-induced liver injury in mice. Biochem. Pharmacol. 2015, 98, 493-501. [CrossRef] [PubMed]

13. Wright, J.M. Phytotoxic effects of some antibiotics. Ann. Bot. 1951, 15, 493-499. [CrossRef]

14. Margulis, L.; Neviackas, J.A.; Banerjee, S. Cilia regeneration in stentor: Inhibition, delay and abnormalities induced by Griseofulvin. J. Protozool. 1969, 16, 660-667. [CrossRef] [PubMed]

15. Hashimoto, T. Fish-toxicity problems of pesticides in Japan-The present situation and the policies of the ministry of agriculture and forestry. PANS Pest Artic. News Summ. 1969, 15, 325-329. [CrossRef] 
16. Iglesias, A.; Nebot, C.; Vázquez, B.I.; Miranda, J.M.; Abuín, C.M.F.; Cepeda, A. Detection of veterinary drug residues in surface waters collected nearby farming areas in Galicia, North of Spain. Environ. Sci. Pollut. Res. Int. 2014, 21, 2367-2377. [CrossRef] [PubMed]

17. Chitescu, C.L.; Kaklamanos, G.; Nicolau, A.I.; Stolker, A.A.M.L. High sensitive multiresidue analysis of pharmaceuticals and antifungals in surface water using U-HPLC-Q-exactiveorbitrap HRMS. Application to the Danube river basin on the Romanian territory. Sci. Total Environ. 2015, 532, 501-511. [CrossRef]

18. Kuroda, K.; Nakada, N.; Hanamoto, S.; Inaba, M.; Katayama, H.; Do, A.T.; Nga, T.T.V.; Oguma, K.; Hayashi, T.; Takizawa, S. Pepper mild mottle virus as an indicator and a tracer of fecal pollution in water environments: Comparative evaluation with wastewater-tracer pharmaceuticals in Hanoi, Vietnam. Sci. Total Environ. 2015, 506, 287-298. [CrossRef]

19. Kim, J.; Yoon, S.; Lee, S.; Narumiya, M.; Nakada, N.; Han, I.; Tanaka, H. Occurrence and fate of PPCPs wastewater treatment plants in Korea. In Proceedings of the 2nd International Conference on Environment and Industrial Innovation, Singapore, 2-3 June 2012; pp. 57-61.

20. Okuda, T.; Yamashita, N.; Tanaka, H.; Matsukawa, H.; Tanabe, K. Development of extraction method of pharmaceuticals and their occurrences found in Japanese wastewater treatment plants. Environ. Int. 2009, 35, 815-820. [CrossRef]

21. Petit, K.; Mondeguer, F.; Roquebert, M.; Biard, J.; Pouchus, Y. Detection of griseofulvin in a marine strain of Penicilliumwaksmanii by ion trap mass spectrometry. J. Microbiol. Methods 2004, 58, 59-65. [CrossRef]

22. Kahsay, G.; Adegoke, A.O.; Van Schepdael, A.; Adams, E. Development and validation of a reversed phase liquid chromatographic method for analysis of griseofulvin and impurities. J. Pharma. Biomed. Anal. 2013, 80, 9-17. [CrossRef] [PubMed]

23. Liu, Q.; Xu, X.; Wang, L.; Lin, L.; Wang, D. Simultaneous determination of forty-two parent and halogenated polycyclic aromatic hydrocarbons using solid-phase extraction combined with gas chromatography-mass spectrometry in drinking water. Ecotoxicol. Environ. Saf. 2019, 181, 241-247. [CrossRef] [PubMed]

24. Huang, D.-L.; Wang, R.-Z.; Liu, Y.-G.; Zeng, G.-M.; Lai, C.; Xu, P.; Lu, B.-A.; Xu, J.-J.; Wang, C.; Huang, C. Application of molecularly imprinted polymers in wastewater treatment: A review. Environ. Sci. Pollut. Res. 2015, 22, 963-977. [CrossRef] [PubMed]

25. Martín-Esteban, A. Recent molecularly imprinted polymer-based sample preparation techniques in environmental analysis. Trend. Environ. Anal. Chem. 2016, 9, 8-14. [CrossRef]

26. Luo, Z.; Zeng, A.; Zheng, P.; Guo, P.; Du, W.; Du, K.; Fu, Q. Preparation of surface molecularly imprinted polymers as the solid-phase extraction sorbents for the specific recognition of penicilloic acid in penicillin. Anal. Methods 2014, 6, 7865-7874. [CrossRef]

27. Xu, H.; Pan, W.; Song, D.; Yang, G. Development of an improved liquid phase microextraction technique and its application in the analysis of flumetsulam and its two analogous herbicides in soil. J. Agric. Food Chem. 2007, 55, 9351-9356. [CrossRef]

28. Zielińska, K.; van Leeuwen, H.P.; Thibault, S.; Town, R.M. Speciation analysis of aqueous nanoparticulate diclofenac complexes by solid-phase microextraction. Langmuir 2012, 28, 14672-14680. [CrossRef]

29. Aguilera-Herrador, E.; Lucena, R.; Cárdenas, S.; Valcárcel, M. Direct coupling of ionic liquid based single-drop microextraction and GC/MS. Anal. Chem. 2008, 80, 793-800. [CrossRef]

30. Pastor-Belda, M.; Garrido, I.; Campillo, N.; Viñas, P.; Hellín, P.; Flores, P.; Fenoll, J. Determination of spirocyclictetronic/tetramic acid derivatives and neonicotinoid insecticides in fruits and vegetables by liquid chromatography and mass spectrometry after dispersive liquid-liquid microextraction. Food Chem. 2016, 202, 389-395. [CrossRef]

31. Abdolmohammad-Zadeh, H.; Rahimpour, E. CoFe2O4 nano-particles functionalized with 8-hydroxyquinoline for dispersive solid-phase micro-extraction and direct fluorometric monitoring of aluminum in human serum and water samples. Anal. Chim. Acta 2015, 881, 54-64. [CrossRef]

32. Zhu, H.; Chen, W.; Li, Z.; He, J.; Tang, X.; Wang, C. Extraction of natural estrogens in environmental waters by dispersive multiwalled carbon nanotube-based agitation-assisted adsorption and ultrasound-assisted desorption. Anal. Methods 2014, 6, 1235-1241. [CrossRef]

33. Bashir, K.; Guo, P.; Chen, G.; Li, Y.; Ge, Y.; Shu, H.; Fu, Q. Synthesis, characterization, and application of griseofulvin surface molecularly imprinted polymers as the selective solid phase extraction sorbent in rat plasma samples. J. Arab. Chem. 2019. [CrossRef] 
34. Mallick, A.; Saha, S.; Pachfule, P.; Roy, S.; Banerjee, R. Selective CO2 and H2 adsorption in a chiral magnesium-based metal organic framework (Mg-MOF) with open metal sites. J. Mater. Chem. 2010, 20, 9073. [CrossRef]

35. Karlsson, J.G.; Andersson, L.I.; Nicholls, I.A. Probing the molecular basis for ligand-selective recognition in molecularly imprinted polymers selective for the local anaesthetic bupivacaine. Anal. Chim. Acta 2001, 435, 57-64. [CrossRef]

36. Beltran, A.; Marcé, R.; Cormack, P.; Borrull, F. Synthesis by precipitation polymerisation of molecularly imprinted polymer microspheres for the selective extraction of carbamazepine and oxcarbazepine from human urine. J. Chromatogr. A 2009, 1216, 2248-2253. [CrossRef]

37. Fukuhara, T.; Iwasaki, S.; Kawashima, M.; Shinohara, O.; Abe, I. Adsorbability of estrone and $17 \beta$-estradiol in water onto activated carbon. Water Res. 2006, 40, 241-248. [CrossRef]

38. Guo, P.; Luo, Z.; Xu, X.; Zhou, Y.; Zhang, B.; Chang, R.; Du, W.; Chang, C.; Fu, Q. Development of molecular imprinted column-on line-two dimensional liquid chromatography for selective determination of clenbuterol residues in biological samples. Food Chem. 2017, 217, 628-636. [CrossRef]

39. Schwarz, H.; Waldman, B.; Madrid, V. GLC determination of griseofulvin in human plasma. J. Pharma. Sci. 1976, 65, 370-372. [CrossRef]

40. Mistri, H.N.; Jangid, A.G.; Sanyal, M.; Shrivastav, P. Electrospray ionization LC-MS/MS validated method to quantify griseofulvin in human plasma and its application to bioequivalence study. J. Chromatogr. B 2007, 850, 318-326. [CrossRef]

41. Wei, B.; Liang, D.; Bates, T.R. Development and validation of a HPLC method to determine griseofulvin in rat plasma: Application to pharmacokinetic studies. Anal. Chem. Insights 2008, 3, 103-109. [CrossRef]

(C) 2019 by the authors. Licensee MDPI, Basel, Switzerland. This article is an open access article distributed under the terms and conditions of the Creative Commons Attribution (CC BY) license (http://creativecommons.org/licenses/by/4.0/). 